Disponível em www.scielo.br/paideia

\title{
Opiniões dos adolescentes do ensino médio sobre o relacionamento familiar e seus planos para o futuro
}

\author{
Elisângela Maria Machado Pratta \\ Manoel Antônio dos Santos \\ Universidade de São Paulo, Ribeirão Preto, Brasil
}

\begin{abstract}
Resumo: Este estudo objetivou levantar pontos positivos e negativos do relacionamento familiar segundo a opinião de adolescentes usuários e não usuários de substâncias psicoativas, bem como identificar os planos que esses grupos apresentam para o futuro. Participaram 568 adolescentes que responderam a um questionário de auto-preenchimento. As análises envolveram a descrição da distribuição das variáveis e a aplicação do teste qui-quadrado. Os resultados mostraram que, no que se refere aos pontos positivos e negativos do relacionamento familiar, foram destacados aspectos referentes à "dinâmica familiar". Quanto aos pontos negativos, no grupo de adolescentes que já utilizaram ou utilizam drogas, o principal tema foi a "falta de diálogo" na família. Por fim, os principais planos para o futuro que os adolescentes de ambos os grupos apresentaram envolvem questões referentes à família e à preparação e atuação profissional. Esses dados fornecem informações relevantes para o planejamento de estratégias preventivas ao uso de drogas na adolescência.
\end{abstract}

Palavras-chave: Uso de drogas. Adolescência. Família. Diálogo. Futuro.

\section{Opinions of high schoolers about family relationship and their plans for the future}

\begin{abstract}
The aim of this study was to survey the positive and negative points within the family relationship according to the opinion of drug addicted and non-drug addicted adolescents and to identify the plans they have for their future. 568 adolescents answered a self-filling questionnaire. The analysis of distribution of variables and chi-square test showed as positive points that the "family dynamics" were highlighted. Regarding to the negative points, among the addicted adolescents, the major issue was the "lack of dialogue" within the family. Regarding the main plans for the future, adolescents from both groups mentioned family and professional preparation and performance. This data presents significant information for the development of preventive strategies against the drug addiction during adolescence.
\end{abstract}

Keywords: Drug addiction. Adolescence. Family. Dialogue. Future.

\section{Opiniones de los adolescentes del bachillerato sobre el relacionamiento famili- ar y sus planes para el futuro}

Resumen: El objetivo fue identificar los puntos positivos y negativos del relacionamiento familiar, según la opinión de adolescentes usuarios y no usuarios de substancias psicoactivas, identificando sus planes para el futuro. 568 adolescentes respondieron un cuestionario de auto-respuesta. Los análisis de la descripción de las variables y del test qui-cuadrado, mostraron que con relación a los puntos positivos se destacaron aspectos relacionados con la "dinámica familiar". El punto negativos indicado por los adolescentes usuarios de drogas fue la "falta de dialogo" en la familia. Finalmente, los planes para el futuro que los adolecentes de ambos grupos se referían a la familia y preparación profesional. Tornando relevantes estas informaciones para la programación de estrategias preventivas al uso de drogas en la adolescencia.

Palabras clave: Uso de drogas. Adolescencia. Familia. Dialogo. Futuro. 


\section{Introdução}

A família corresponde a uma instituição que exerce uma influência significativa durante todo o processo de desenvolvimento do indivíduo, sendo encarada, geralmente, como um grupo que apresenta uma organização complexa e que está inserido em um contexto social mais amplo, mantendo com este constante interação (Biasoli-Alves, 2004).

Sendo assim, é na família que se dimensiona e têm início as práticas da educação e da socialização das crianças (Antón, 1998; Schenker \& Minayo, 2003), estabelecendo-se formas e limites para as relações que são mantidas entre as gerações mais novas e mais velhas (Simionato-Tozo \& BiasoliAlves, 1998). É a partir do processo socializador que o indivíduo elabora sua identidade e subjetividade (Romanelli, 2002), adquirindo, no interior da família, os valores, as normas, as crenças, as idéias, os modelos e os padrões comportamentais necessários para sua atuação social (Antón, 1998). A família apresenta, também, um papel relevante em relação à conservação e mudança de hábitos, costumes e comportamentos entre os membros que a compõem e entre as gerações (Suárez \& Galera, 2004).

Refletindo sobre a importância da família para o desenvolvimento dos indivíduos, faz-se necessário pontuar que as influências exercidas por essa instituição variam de acordo com as transformações inerentes ao próprio âmbito familiar, as quais exigem adaptações constantes nas relações estabelecidas entre os membros que constituem a mesma (Sudbrack, 2001). Isso porque a familia, como grupo social, também passa por um ciclo vital, que é dinâmico e constituído por determinadas etapas, marcadas tanto por eventos críticos previsíveis (casamento, adolescência dos filhos), quanto por eventos críticos não previsíveis (doenças, perdas). Tais acontecimentos apresentam grande impacto no contexto familiar, provocando uma crise que afeta, direta ou indiretamente, a todos os seus membros, como acontece, por exemplo, no período da adolescência, considerado como um estágio do ciclo vital familiar que provoca intensas mudanças relacionais, especialmente entre pais e filhos (Sudbrack, 2001), pois paralelamente às transformações dos próprios jovens, a família passa por uma etapa de intensas mudanças em seu padrão de funcionamento (Pedrebon, 2002).

Isso geralmente acontece pois, segundo Cerveny e Berthoud (2001), pais e filhos encontramse em momentos diferentes de transformação, ou seja, os adolescentes costumam questionar valores e regras familiares, preocupando-se intensamente com o futuro, enquanto seus pais se encontram em uma etapa de questionamento profissional, de reflexão e de transformação, também repensando o futuro. É possível pontuar, então, que existe um cruzamento entre o ciclo vital da família e o de seus membros, sendo que cada etapa envolve processos emocionais de transição, bem como mudanças primordiais para dar seguimento ao desenvolvimento tanto individual quanto familiar (Carter \& McGoldrick, 1995; Simionato-Tozo, 2000).

Encarada como uma fase do Ciclo de Vida Familiar, a adolescência apresenta algumas tarefas particulares, que envolvem todos os membros da família (Penso \& Sudbrack, 2004). Assim, pode-se dizer que esta etapa se constitui, para o indivíduo que a vivencia, como uma fase de transição da infância para a idade adulta, evoluindo de um estado de intensa dependência para uma condição de autonomia pessoal (Silva \& Mattos, 2004) e de uma condição de necessidade de controle externo para o autocontrole (Biasoli-Alves, 2001), sendo tal momento marcado por uma série de rápidas e intensas mudanças evolutivas nos sistemas biológicos, psicológicos e sociais (Marturano, Elias \& Campos, 2004).

A adolescência corresponde a um período de descobertas dos próprios limites, de curiosidade por experiências novas, de questionamentos dos valores e das normas familiares e de grande adesão aos valores e normas referentes ao grupo de amigos, de rupturas e de aprendizados, sendo uma etapa caracterizada pela necessidade de integração social, pela busca da auto-afirmação e da independência individual e definição da identidade sexual (Schencker \& Minayo, 2003; Silva \& Mattos, 2004).

$\mathrm{Na}$ travessia desse processo os adultos desempenham um papel central, uma vez que oferecem a base inicial ao indivíduo, no que diz respeito às regras e normas essenciais para o convívio em sociedade, bem como atuam como modelos 
introjetados, geralmente como ideais, cujas atitudes e comportamentos serão transmitidos (Biasoli-Alves, 2001). Além disso, a importância da família para o jovem repousa também na possibilidade de manter, nessa etapa, o eixo de referências simbólicas que a organização familiar representa, como lugar de apego, proteção, segurança, valores e informações confiáveis, sendo necessário que, para operar essa função, a família abra espaço para esse "outro" que está se consolidando (Sarti, 2004). Assim, é necessário que a família opere como fonte de apoio e de limites para o adolescente, mas que também apresente maior flexibilidade das fronteiras e dos papéis familiares, além de legitimar o princípio da negociação nas interações e uma nova modulação da autoridade parental (Penso \& Sudbrack, 2004).

É necessário ressaltar ainda que o processo de transição adolescente não afeta apenas os indivíduos que estão passando por esse período, mas também as pessoas que convivem diretamente com os mesmos, principalmente a família, constituindo-se, portanto, como um processo freqüentemente difícil e doloroso tanto para os adolescentes quanto para seus pais. Isso porque as grandes mudanças oriundas dessa etapa propiciam o surgimento de fatores e questões que repercutem sobre o jovem e sua família (Santos, 2005). Assim, esse período do desenvolvimento apresenta algumas condições especiais para a emergência de uma série de problemas e conflitos que não raro eclodem dentro do contexto familiar (Antón, 1998), sendo que muitos estudos enfatizam que há um aumento das brigas e disputas entre pais e filhos durante os anos da adolescência (Wagner, Falcke, Silveira \& Mosmann, 2002), uma vez que a necessidade de negociação constante, inerente a essa etapa, aumenta o potencial de conflitos entre as gerações (Marturano \& cols., 2004). Entretanto, segundo essas mesmas autoras, um conflito bem negociado pode levar ao crescimento, tanto para os filhos quanto para os pais.

Nesse sentido, muitas famílias adotam estratégias específicas de resolução de conflitos, buscando adaptarem-se às transformações dos filhos adolescentes e às mudanças da própria família, bem como dos próprios pais. Esses recursos envolvem compartilhar os problemas com o adolescente, flexibilizando as fronteiras, depositar confiança no filho, preocupar-se em orientar, oferecer modelos e dialogar (Cerveny \& Berthoud, 2001). Essa adequação, portanto, depende da capacidade dos pais em equilibrar a supervisão da qual o adolescente ainda necessita com a concessão da independência que o mesmo busca (Marturano \& cols., 2004).

Além disso, estudos apontam que, a despeito das dificuldades enfrentadas, a família continua atuando nessa etapa da vida como um referencial importante para o adolescente, o que se reflete nas avaliações que os jovens fazem sobre o relacionamento entre pais e filhos, do que gostam e do que não gostam na família (Ribeiro, 1992), bem como nos planos e escolhas que os mesmos apresentam para o futuro, uma vez que entre suas preocupações a constituição de família e a profissionalização ganham destaque (Wagner, Falcke \& Meza, 1997).

Nesse contexto, em um estudo realizado por Ribeiro (1992), constatou-se que, entre os aspectos que os adolescentes mais apreciam na família, o tema mais freqüente foi "união", seguido por "amizade", "amor" e "sinceridade". Por outro lado, Wagner e cols. (1997), em um estudo com 60 adolescentes de 12 a 17 anos provenientes de famílias originais e reconstituídas, obtiveram dados semelhantes: os adolescentes ressaltaram o "companheirismo/união" e a "afeição" como sendo os aspectos mais valorizados por eles no âmbito familiar, seguidos pela questão da "liberdade".

Uma questão que pode ser formulada, quando levamos em consideração os índices alarmantes de uso de drogas na adolescência, é: como se configuram esses elementos no caso dos adolescentes que utilizam ou já utilizaram substâncias psicoativas?

Esse é um tema que merece atenção, uma vez que estudos têm apontado que, atualmente, o consumo de drogas por adolescentes apresenta altas taxas de prevalência, ocorrendo cada vez mais em etapa precoce (Carranza \& Pedrão, 2005; Toscano Jr, 2001), ressaltando-se também que o primeiro contato com a droga geralmente ocorre na adolescência, uma vez que essa fase é marcada por muitas e profundas mudanças tanto físicas quanto psíquicas, que tornam o adolescente mais vulnerável (De Micheli \& Formigoni, 2000; Rebolledo, Medina \& Pillon 2004; 
Rodriguez \& Luis, 2004; Schenker \& Minayo, 2005; Silva \& Mattos, 2004).

Entretanto, apesar de os adolescentes serem encarados como um grupo de risco, no que diz respeito ao uso de substâncias psicoativas, a literatura, no geral, aponta que os motivos que podem levá-los a utilizar drogas são variados. Nesse sentido, segundo Schenker e Minayo (2005), os fatores de risco e de proteção em relação ao uso de drogas estão relacionados a seis domínios da vida (o individual, o familiar, o escolar, o midiático, os amigos e a comunidade de convivência), que apresentam relações entre si. No caso do domínio familiar, aspectos como fortes vínculos, o estabelecimento de regras e limites claros e coerentes, o monitoramento e a supervisão, o apoio e a comunicação são considerados como fatores que protegem o adolescente do uso de drogas.

Dessa maneira, torna-se importante compreender como o adolescente que já utilizou ou utiliza substâncias psicoativas avalia o relacionamento familiar, bem como o que o mesmo planeja para o seu futuro, uma vez que esses elementos podem contribuir para a elaboração de estratégias que visem o fortalecimento dos fatores de proteção ao uso abusivo de drogas no ambiente familiar. Com base nessas considerações, o presente estudo objetivou: a) levantar os pontos positivos e negativos do relacionamento com os pais, segundo a opinião de adolescentes usuários e não usuários de drogas; $b$ ) identificar os planos que os adolescentes de ambos os grupos apresentam para o futuro; c) verificar se existem diferenças significativas entre os envolvidos no que diz respeito à avaliação do relacionamento com os pais e aos planos dos mesmos para o futuro.

\section{Materiais e método}

Esse estudo teve como população-alvo adolescentes inseridos no ensino médio da cidade de São Carlos. Para a condução da pesquisa foi selecionada uma amostra, obtida de forma sistemática em dois estágios. No primeiro foram sorteadas as escolas e, no segundo estágio, levantadas as turmas dentre as que haviam sido previamente sorteadas. Assim, participaram desse estudo 568 adolescentes de ambos os sexos (45,1\% do sexo masculino e $54,9 \%$ do feminino) com idades variando entre $14 \mathrm{e}$
20 anos, de diferentes camadas sociais, que estavam cursando o ensino médio em escolas públicas e privadas da cidade de São Carlos, SP, devidamente autorizados pelos pais ou responsáveis que assinaram um Termo de Consentimento Livre e Esclarecido. Da totalidade de adolescentes recrutados foram considerados, para fins de análise, aqueles que já tinham feito ou estavam fazendo uso de substâncias psicoativas, exceto álcool e tabaco $(n=134)$ e aqueles que nunca utilizaram nenhum tipo de substância psicoativa $(\mathrm{n}=57)$.

O instrumento para a coleta de dados era anônimo e de auto-preenchimento, tendo sido previamente testado em um estudo piloto com a finalidade de corrigir as imperfeições e definir o procedimento de coleta de dados. Esse instrumento, denominado "Adolescente e família: caracterização dos relacionamentos interpessoais", é composto por cinco questões fechadas e quatro abertas, que versam sobre o relacionamento com os pais, os aspectos positivos e negativos observados pelos adolescentes no seu relacionamento com eles e os seus planos para o futuro. Destaca-se que as cinco questões fechadas foram selecionadas do "Questionário sobre o Uso de Drogas" desenvolvido por Galduróz, Noto e Carlini (1997) e aplicado a estudantes do ensino fundamental e médio de dez capitais brasileiras. Por outro lado, as questões abertas foram elaboradas exclusivamente para o presente estudo.

A aplicação do questionário deu-se coletivamente em sala de aula, sem a presença do professor, em dias previamente agendados com a escola, os professores e os alunos, sendo distribuídos simultaneamente e sem determinação do tempo para término de seu preenchimento. Com a finalidade de garantir o sigilo das respostas os adolescentes depositavam o questionário preenchido em uma urna lacrada.

Os dados coletados foram analisados estatisticamente, utilizando-se para tanto o programa SPSS (Statistical Package for the Social Sciences), versão 10.0, efetuando-se os seguintes cálculos: a) levantamento das freqüências absoluta e relativa para as variáveis em questão; b) cálculo do Qui-quadrado.

No caso das questões abertas que envolviam a indicação dos pontos positivos e negativos 
observados pelos adolescentes no relacionamento com os pais, os dados obtidos foram trabalhados por meio de Análise de Conteúdo, buscando integrar categorias previamente descritas na literatura sobre a temática em foco com as informações trazidas pelos participantes (Olabuenaga, 1996). Para tanto foi utilizado como referencial de análise o sistema de categorias de significado desenvolvido por Ribeiro (1992), em um estudo que tinha por finalidade verificar o relacionamento familiar por meio da percepção dos adolescentes sobre a relação com seus pais e o relacionamento conjugal (ou seja, de seus pais). Sendo assim, as categorias empregadas foram: dinâmica da família, aspectos afetivos, membros da família, aspectos éticos-morais, situações de lazer, aspectos utilitários da família e concepção mística. Além dessas mostrou-se necessário o desenvolvimento de novas categorias, uma vez que muitas das respostas encontradas não se enquadravam em nenhuma das anteriormente definidas.

Em relação aos pontos negativos utilizaramse as mesmas categorias para a classificação das respostas, ressaltando-se, nesse caso, os aspectos em falta ou que não eram adequados, segundo a percepção dos adolescentes, em cada uma delas. Por exemplo, na categoria "dinâmica familiar" foram inseridos temas como desunião, falta de diálogo, dificuldades de relacionamento. Esse procedimento foi adotado para cada uma das categorias utilizadas no estudo, destacando-se que, também no caso dos pontos negativos, foi necessário desenvolver novas categorias.

Por outro lado, as questões referentes ao que "pode ser melhorado no relacionamento dos adolescentes com os pais para este ser mais positivo" e "sobre os planos dos adolescentes para o futuro", inseridas no instrumento de coleta de dados, foram analisadas buscando-se, primeiramente, realizar uma categorização das respostas, utilizando-se a metodologia de Análise de Conteúdo Temática Freqüencial de Bardin (1977).

\section{Resultados}

As Tabelas 1 e 2 apresentam os dados sobre os pontos positivos e negativos que os adolescentes evidenciaram sobre seu relacionamento com os pais. Em linhas gerais, verificou-se uma grande variabilidade de respostas apresentadas pelos dois grupos participantes do estudo. É importante destacar que, nesse caso, o número de respostas ultrapassou o de respondentes, pois os mesmos poderiam citar mais de um ponto positivo no relacionamento deles com os pais.

A Tabela 1 apresenta as categorias de resposta encontradas no que diz respeito aos pontos positivos do relacionamento com os pais.

Tabela 1. Levantamento dos pontos positivos que os adolescentes constataram no relacionamento dos mesmos com seus pais tomando-se por base as categorias gerais de uso de substâncias.

\begin{tabular}{|l|c|c|c|c|}
\hline \multirow{2}{*}{} & \multicolumn{2}{|c|}{$\begin{array}{c}\text { Usuário } \\
(\mathbf{n = 1 3 4 )}\end{array}$} & \multicolumn{2}{c|}{$\begin{array}{c}\text { Não usuário } \\
(\mathbf{n}=\mathbf{5 7})\end{array}$} \\
\cline { 2 - 5 } & $\mathrm{n}$ & $\%$ & $\mathrm{n}$ & $\%$ \\
\hline Dinâmica da família & 125 & 93,2 & 56 & 98,2 \\
\hline Aspectos afetivos & 83 & 61,9 & 47 & $82,4 *$ \\
\hline Aspectos ético-morais & 39 & 29 & 10 & 17,5 \\
\hline Situações de lazer & 13 & 9,7 & 4 & 7 \\
\hline $\begin{array}{l}\text { Características gerais dos } \\
\text { pais }\end{array}$ & 11 & 8,2 & 6 & 10,5 \\
\hline $\begin{array}{l}\text { Nenhum/nada } \\
\text { Aspectos utilitários da } \\
\text { família }\end{array}$ & 8 & 6 & 0 & 0 \\
\hline Outros & 4 & 3 & 2 & 3,5 \\
\hline
\end{tabular}

* Diferença estatisticamente significativa entre os grupos de adolescentes (Teste do Qui-quadrado) $(\mathrm{p}<0,05)$.

Os dados retratados na Tabela 1 mostram que os principais pontos positivos citados pelos adolescentes encontram-se na categoria "dinâmica familiar", tanto para o grupo de usuários quanto para o de não usuários (93,2\% e 98,2\% respectivamente), na qual estão inseridos temas como união, relacionamento e comunicação na família.

Em seguida os principais pontos positivos destacados no relacionamento familiar recaem, segundo as opiniões dos dois grupos de adolescentes, sobre os "aspectos afetivos", cujos temas envolvem elementos como amizade, amor, carinho, 
compreensão, dedicação. Foram observadas diferenças significativas entre os dois grupos no que se refere a esse aspecto $(\mathrm{p}<0,05)$, sendo que os adolescentes não usuários ressaltam mais os aspectos afetivos do relacionamento familiar como tendo valor positivo do que os usuários.

Em terceiro lugar aparece a categoria "aspectos éticos-morais", com $29 \%$ de indicações para o grupo de adolescentes usuários e 17,5\% para o de não usuários, envolvendo temas como honestidade, respeito, lealdade, confiança e sinceridade.

É interessante destacar que, no grupo de usuários, no que se refere à categoria "dinâmica familiar", o tema que obteve a maior frequiência de indicações foi "diálogo" (54,5\%). Por outro lado, na categoria "aspectos afetivos", o tema que apresentou maior freqüência de respostas para esse grupo foi "compreensão", seguido por "amizade" $(22,4 \%)$ e "amor" (16,4\%). Para o grupo de não usuários, na categoria "dinâmica familiar" a temática com maior frequiência foi "diálogo" (52,6\%), enquanto que na de "aspectos afetivos" o destaque apareceu para os temas "amizade" $(26,3 \%)$ e "amor" $(17,5 \%)$.

A Tabela 2, por sua vez, apresenta as categorias de respostas referentes aos pontos negativos indicados pelos adolescentes sobre o seu relacionamento com os pais.

Na Tabela 2 é possível constatar, novamente, grande variabilidade de respostas. Entretanto, é importante destacar que essa diversidade foi maior para o grupo de adolescentes usuários do que para o de não usuários.

Em ambos os grupos a categoria que apresentou as maiores frequiências foi "dinâmica familiar" (52,2\% para o grupo de usuários e $47,4 \%$ para o de não usuários), ou seja, os principais pontos negativos observados pelos adolescentes no relacionamento com seus pais incluíam: problemas de relacionamento, falta de diálogo, de união, de proximidade, de atenção. Dentro dessa categoría, o tema com maior frequiência para o grupo de usuários foi a "falta de diálogo" (44\%), seguido por "brigas" (30\%). No caso dos não usuários, os temas destacados foram "severidade" $(26,3 \%)$ e "brigas' $(15,7 \%)$.

A segunda categoria com maior frequiência de respostas para ambos os grupos foi "aspectos ético-
Tabela 2. Levantamento dos pontos negativos que os adolescentes, tanto usuário quanto não usuário constataram no relacionamento dos mesmos com seus pais

\begin{tabular}{|l|c|c|c|c|}
\hline \multirow{2}{*}{} & \multicolumn{2}{|c|}{$\begin{array}{c}\text { Usuário } \\
(\mathbf{n = 1 3 4 )}\end{array}$} & \multicolumn{2}{c|}{$\begin{array}{c}\text { Não usuário } \\
(\mathbf{n}=\mathbf{5 7})\end{array}$} \\
\cline { 2 - 5 } & $\mathrm{n}$ & $\%$ & $\mathrm{n}$ & $\%$ \\
\hline Dinâmica da família & 70 & 52,2 & 27 & 47,4 \\
\hline Aspectos afetivos & 23 & $17,1^{*}$ & 1 & 1,7 \\
\hline Aspectos ético-morais & 49 & 36,6 & 9 & 15,8 \\
\hline $\begin{array}{l}\text { Características gerais dos } \\
\text { pais }\end{array}$ & 18 & 13,4 & 4 & 7 \\
\hline $\begin{array}{l}\text { Aspectos utilitários da } \\
\text { família }\end{array}$ & 3 & 2,2 & 0 & 0 \\
\hline Nenhum/nada & 11 & 8,2 & 2 & 3,5 \\
\hline $\begin{array}{l}\text { Consumo de substâncias } \\
\text { psicoativas }\end{array}$ & 2 & 1,4 & 3 & 5,2 \\
\hline Outros & 8 & 6 & 28 & 49,1 \\
\hline
\end{tabular}

* Diferença estatisticamente significativa entre os grupos de adolescentes (Teste do Qui-quadrado) $(\mathrm{p}<0,05)$.

morais"; ou seja, os adolescentes avaliaram como pontos negativos: autoritarismo, falta de respeito, de confiança, de responsabilidade, de paciencia, entre outros. Para os usuários, os temas destacados incluíram: "autoritarismo" e "controle", enquanto que no de não usuários aparecereu o "autoritarismo", seguido por "mentiras".

Na comparação entre os dois grupos verificouse serem estatisticamente significativas as diferenças na categoria "aspectos afetivos" $(\mathrm{p}<0,05)$, indicando que os usuários ressaltaram mais pontos negativos do relacionamento com os pais (como, por exemplo, falta de amor, de companheirismo, de amizade, entre outros) do que os adolescentes do grupo de não usuários.

Os resultados apresentados na Tabela 3 buscam retratar as opiniões dos adolescentes participantes do estudo a respeito do que poderia ser melhorado no relacionamento deles com os pais no dia-a-dia.

Observando-se os dados descritos na Tabela 3 verifica-se que a categoria mais freqüente para o grupo de usuários é a da "dinâmica familiar" $(31,3 \%)$ 
Tabela 3. Levantamento dos pontos a serem melhorados no relacionamento com os pais, segundo a opinião dos próprios adolescentes

\begin{tabular}{|l|c|c|c|c|}
\hline \multirow{2}{*}{} & \multicolumn{2}{|c|}{$\begin{array}{c}\text { Usuário } \\
\text { (n=134) }\end{array}$} & \multicolumn{2}{c|}{$\begin{array}{c}\text { Não usuário } \\
\text { (n=57) }\end{array}$} \\
\cline { 2 - 5 } & $\mathrm{n}$ & $\%$ & $\mathrm{n}$ & $\%$ \\
\hline Não sei & 8 & 6 & 2 & 3,5 \\
\hline Nada & 23 & 17,2 & 16 & $28,1 *$ \\
\hline Dinâmica familiar & 42 & 31,3 & 12 & $21^{*}$ \\
\hline Aspectos afetivos & 9 & 6,7 & 1 & 1,7 \\
\hline Aspectos éticos-morais & 9 & 6,7 & 3 & 5,2 \\
\hline $\begin{array}{l}\text { Aspectos utilitários da } \\
\text { família }\end{array}$ & 1 & 0,7 & 0 & 0 \\
\hline Características dos pais & 3 & 2,2 & 0 & 0 \\
\hline Outros & 6 & 4,5 & 3 & 5,3 \\
\hline
\end{tabular}

* Diferença estatisticamente significativa entre os grupos de adolescentes (Teste do Qui-quadrado) $(\mathrm{p}<0,05)$.

e que os principais pontos a serem melhorados seriam: o diálogo, a compreensão e o tempo que passam juntos.

Ainda no que se refere a essa categoria, o percentual obtido para os usuários foi significantemente maior quando comparado ao índice verificado para o grupo de não usuários $(31,3 \%$ e $21 \%$, respectivamente) $(\mathrm{p}<0,05)$, o que indica que, para os usuários, diferentemente do que se observa com os não usuários, os pontos que necessitam ser melhorados no relacionamento com os pais referem-se mais a aspectos da dinâmica familiar.

Os adolescentes não usuários, por sua vez, apresentaram uma porcentagem significativamente maior na categoria "nada" $(p<0,05)$. Ou seja, não vêem necessidade de melhorar algo no relacionamento com os pais, uma vez que se consideram contentes e satisfeitos com eles, diferentemente do que se verificou no grupo de adolescentes usuários.

Por fim, a Tabela 4 apresenta o levantamento dos planos dos adolescentes para o futuro.

Os dados descritos na Tabela 4 mostram que os principais planos dos adolescentes envolvem
Tabela 4. Levantamento dos planos dos adolescentes para o futuro

\begin{tabular}{|l|c|c|c|c|}
\hline \multirow{2}{*}{} & \multicolumn{2}{|c|}{$\begin{array}{c}\text { Usuário } \\
(\mathbf{n = 1 3 4})\end{array}$} & \multicolumn{2}{c|}{$\begin{array}{c}\text { Não usuário } \\
(\mathbf{n = 5 7})\end{array}$} \\
\cline { 2 - 5 } & $\mathrm{n}$ & $\%$ & $\mathrm{~N}$ & $\%$ \\
\hline Casar e ter filhos & 3 & 2,2 & 0 & 0 \\
\hline Fazer faculdade/estudar & 37 & 27,6 & 18 & $31,6^{*}$ \\
\hline $\begin{array}{l}\text { Fazer faculdade e } \\
\text { constituir família }\end{array}$ & 54 & 40,3 & 5 & $8,8^{*}$ \\
\hline São positivos & 1 & 0,7 & 1 & 1,7 \\
\hline Ser alguém na vida & 2 & 1,5 & 1 & 1,7 \\
\hline $\begin{array}{l}\text { Ter uma } \\
\text { profissão/emprego }\end{array}$ & 6 & 4,5 & 8 & $14 *$ \\
\hline Ainda não tem & 5 & 3,7 & 4 & 7 \\
\hline Não respondeu & 15 & 11,2 & 9 & 15,8 \\
\hline
\end{tabular}

* Diferença estatisticamente significativa entre os grupos de adolescentes (Teste do Qui-quadrado) $(\mathrm{p}<0,05)$.

questões referentes à família e à preparação profissional, com vistas ao ingresso no mundo do trabalho. Para o grupo de usuários a categoria com maior freqüência foi "fazer faculdade e construir família" $(40,4 \%)$. Por outro lado, os não usuários destacaram a categoria "fazer faculdade/estudar" $(33,3 \%)$. E essas duas categorias apresentaram diferenças significativas entre os dois grupos de adolescentes $(\mathrm{p}<0,01)$.

Destaque-se, ainda, que a categoria "ter uma profissão/emprego", apesar de indicar freqüências baixas, apresentou diferenças significativas entre os dois grupos de adolescentes, sendo o percentual para o grupo de não usuários significantemente maior do que para o de usuários (14\% e 4,5\%, respectivamente).

$\mathrm{Na}$ categoria "outros" foram agrupadas as respostas dadas pelos adolescentes que não puderam ser encaixadas nas demais categorias e que apresentaram uma frequiência igual a um. Nessa categoria residual foram inseridas respostas tais como: amor, melhorar a cada dia, morar com a mãe, entre outras. 


\section{Discussão}

Refletindo sobre os dados apresentados, nota-se que a categoria "dinâmica familiar" foi a que apresentou as maiores freqüências para ambos os grupos, tanto no que se refere aos pontos positivos quanto em relação aos negativos do relacionamento dos adolescentes com os pais. Os dois grupos - usuários e não usuários de substâncias psicoativas - apontaram a presença do diálogo como uma característica positiva no relacionamento familiar, contudo, principalmente para os usuários, parece que esse veículo ainda não é explorado em toda a sua amplitude, uma vez que eles apontam a "falta de diálogo" como aspecto negativo desse relacionamento. Essa visão apresentada pelos adolescentes do presente estudo traz insumos importantes para a reflexão, principalmente no que concerne ao valor atribuído ao diálogo no contexto familiar.

O relacionamento pautado no diálogo aparece como um componente fundamental na dinâmica familiar, uma vez que funciona como um dos meios, possivelmente o primordial, para que as relações entre pais e filhos alcancem uma qualidade mais satisfatória e sejam saudáveis (Wagner \& cols., 2002). Entretanto, o diálogo entre pais e filhos deve funcionar como uma troca e não ser encarado como exigência, "cobrança" ou controle da vida do adolescente, uma vez que, dependendo do tipo de comunicação prevalente no contexto familiar, os adolescentes irão conversar com os pais sobre temas específicos, ou seja, tenderão a filtrar as informações que querem passar ou obter deles. Por exemplo, se a comunicação é fechada, caracterizada pelo exercício excessivo da autoridade, a tendência é que pais e filhos conversem sobre assuntos banais do cotidiano, como escola, alimentação, diversão. Por outro lado, se a comunicação for aberta, os membros familiares podem expor sentimentos e questionamentos sem se sentirem ameaçados, conversando sobre temas diferenciados e até mesmo pessoais (Wagner, Carpenedo, Melo \& Silveira, 2005).

$\mathrm{O}$ adolescente tem grande necessidade de se expressar, expor suas ideáis e questionar, e é no âmbito familiar que, muitas vezes, procura estabelecer essa troca. A falta de comunicação e de compreensão pode prejudicar seu bem-estar, distanciando os filhos do ambiente familiar (Antón, 1998; Costa, Teixeira \& Gomes, 2000).

Por outro lado, por meio do diálogo os membros da família tornam-se mais próximos e íntimos, o que transmite segurança tanto aos pais (pois estão atentos ao dia-a-dia dos filhos), quanto aos adolescentes (que se sentem seguros e valorizados), pois, mantendo uma relação mais próxima, é mais fácil para os pais detectarem mudanças no comportamento dos filhos. Wagner e cols (2005) ressaltam que bons níveis de comunicação entre pais e filhos podem funcionar como elemento importante na redução de problemas comportamentais típicos dos adolescentes. Essa proximidade possibilita também maior manifestação de aspectos afetivos, ou seja, elementos como amor, carinho, atenção, dedicação e preocupação tornamse presentes no cotidiano de uma maneira mais intensa. Para o adolescente é importante perceber que os pais têm interesse sobre suas atividades, bem como preocupações, medos, receios, enfim, em relação à sua vida de um modo geral. Assim, pode perceber que sua vida tem significado para o outro.

Os pais, fazendo uso do diálogo desde cedo, podem orientar constantemente os filhos a respeito das mais variadas temáticas, impondo limites claros a serem levados em consideração, mas também expondo seus sentimentos, aspectos que podem funcionar como fatores de proteção em relação ao consumo de substâncias psicoativas pelos adolescentes (Schenker \& Minayo, 2003).

Complementando essa questão, é interessante ressaltar que, na perspectiva dos usuários, elementos como diálogo, compreensão e tempo de convivência com os pais são os principais pontos da dinâmica familiar que devem ser melhorados. A literatura aponta que, no que concerne ao tempo de convivência, pais e filhos adolescentes tendem a interagir e a realizar menos coisas juntos fora de casa do que antes (Marturano \& cols., 2004). Os dados do presente estudo revelaram que esse é um ponto que necessita ser revisto pelas famílias, porque uma convivência mais próxima é fundamental nessa etapa do desenvolvimento. Além disso, a preocupação em dividir momentos, planejar e compartilhar atividades dentro e fora do ambiente familiar são elementos que 
podem levar à manutenção de um bom vínculo e interação com os pais, o que, segundo Schenker e Minayo (2005), funcionaria como fatores de proteção frente ao uso de drogas na adolescência.

Quanto aos planos dos adolescentes para o futuro, os dados revelaram que os mesmos envolvem questões referentes à família e à preparação e atuação profissional, destacando-se a importância que eles atribuem à formação acadêmica para o seu futuro.

Esses dados caminham na direção dos que foram obtidos em outros estudos, que buscaram avaliar os projetos de adolescentes para o seu futuro, como o de Wagner e cols. (1997), no qual as três principais categorias de planos foram: realização profissional (30\% de indicações), ser feliz $(26,1 \%)$ e realização pessoal $(25,5 \%)$.

O estudo de Oliveira, Sá, Fischer, Martins e Teixeira (2001) revelou também dados que apontam nessa direção. Os resultados mostraram uma dimensão de futuro entre os jovens, associada à representação que eles têm da educação como elemento central em suas vidas, indicando que o estudo é visto como um facilitador da ascensão social, seja esta garantida por melhor emprego ou profissão, ou assegurada por um elemento abstrato, como "ser alguém na vida" - frase possivelmente associada à busca de sucesso financeiro.

Coutinho e cols. (2005) também identificaram, em seu estudo, uma relação entre escola e futuro, apresentada de duas formas pelos jovens: alguns ressaltando-a como muito importante, por trazer a perspectiva de uma vida melhor e proporcionar um bom futuro, outros percebendo-a negativamente e preocupando-se mais com o trabalhar no futuro, não demonstrando intenção de buscar a qualificação profissional por meio dos estudos. Além disso, essa valorização dos estudos pelos adolescentes pode ter influência dos próprios pais, o que necessitaria ser mais explorado em pesquisas futuras, pois os pais, em suas conversas diárias com os filhos, podem ressaltar a importância do estudar, discutindo suas vivências, facilidades e dificuldades, buscando conscientizar os adolescentes de que a educação formal é um caminho seguro para conseguir o que se deseja na vida.
Destacando ainda a questão do modelo familiar, é necessário pontuar que a geração que atualmente encontra-se na adolescência está sendo educada por pais que, geralmente, vivenciam uma rotina de papéis múltiplos, executando tarefas fora e dentro do ambiente familiar. Ou seja, hoje pai e mãe atuam no mercado de trabalho, por necessidade ou por busca da realização profissional. A família fornece modelos e influencia diretamente os padrões de conduta dos indivíduos, principalmente se estes estiverem "em processo de desenvolvimento, tentando definir os contornos de sua identidade e organizar seu sistema de valores" (Avi \& Santos, 2000), como ocorre tipicamente no período da adolescência.

Esse aspecto vai ao encontro do conhecimento estabelecido na literatura, uma vez que a família, além de influenciar diretamente na aquisição de crenças e valores, tem um papel central na construção dos planos de vida que o adolescente define para si, o que pode ser explicado pelo fato de que, normalmente, é no seio da organização familiar que o projeto pessoal tem início e é dela que o jovem vai sair em busca da realização de seus sonhos e objetivos (Santos, 2005). Portanto, os adolescentes apresentam projetos de vida que remetem a questões comuns que, de certa forma, se repetem de uma geração para outra (Wagner \& cols., 1997), como os planos envolvendo a formação da família e o campo profissional. Porém, este também é um dado que necessitaria ser melhor explorado em pesquisas futuras.

É interessante notar que no grupo de adolescentes usuários a categoria que se destacou nos planos para o futuro foi "fazer faculdade e constituir família”, enquanto que para os não usuários a mais frequiente foi "fazer faculdade/estudar". Podese inferir, então, que os usuários planejam seu futuro pautados prioritariamente por valores que pertencem à esfera familiar e do trabalho, uma vez que estes, possivelmente, representam para eles a conquista de certa estabilidade e segurança, elementos considerados como os únicos caminhos para saída da instabilidade e ameaça de exclusão em que vivem (Coutinho \& cols., 2005).

\section{Considerações finais}

É interessante notar que os dados obtidos, tanto no que diz respeito aos pontos positivos e negativos, 
quanto aos aspectos que necessitam ser melhorados, ressaltam a importância do diálogo e da compreensão dentro do contexto familiar. Isto indica a importância de novos estudos que busquem aprofundar a questão da comunicação na família, tanto de adolescentes usuários quanto de não usuários de substâncias psicoativas, uma vez que o diálogo, o estabelecimento de limites e a confiança são componentes fundamentais no processo de desenvolvimento do indivíduo, particularmente na etapa da adolescência.

Além disso, a comunicação, aliada a outros elementos do contexto familiar (vínculos sólidos e seguros, confiança, proximidade afetiva) corresponde a um instrumento importante para que as relações entre pais e filhos sejam satisfatórias e saudáveis, e para que os pais exerçam sua função de educadores atuando junto aos adolescentes de forma preventiva, principalmente no que diz respeito ao engajamento em comportamentos de risco, como o uso de substâncias psicoativas.

A literatura aponta que aspectos do contexto familiar podem funcionar como fatores de risco e de proteção em relação ao uso de drogas na adolescência. Toscano Jr. (2001) ressalta que problemas de relacionamento entre pais e filhos, relações afetivas precárias, ausência de regras e normas claras dentro do contexto familiar e o uso de drogas pelos pais, podem atuar como fatores de risco para o envolvimento do adolescente com substâncias psicoativas, e acrescenta ainda as situações de conflitos permanentes, dificuldades de comunicação e a falta de monitoramento constante dos filhos por parte dos pais.

Sendo assim, é importante que, ao longo do processo evolutivo, o indivíduo possa compartilhar seus medos, angústias e dúvidas com os pais, uma vez que a família exerce um papel primordial no desenvolvimento humano. Ter o apoio e a compreensão dos familiares é um requisito fundamental para o bem-estar psicológico do indivíduo que atravessa esse período conturbado e marcado por transformações rápidas e intensas. Assim, destacase que a atuação dos pais no dia-a-dia, se adequada, pode ter uma função preventiva eficaz para muitos problemas, inclusive no que se refere ao uso abusivo de substâncias psicoativas (Antón, 1998). Esse autor afirma que criar situações de comunicação e aproveitar os momentos de convivência com os filhos, seja em um passeio, jogos, diversão ou situações de relaxamento, pode contribuir para o desenvolvimento de um clima de confiança e fluidez de comunicação que facilitaria o debate de temas, dilemas, problemas e pontos de vista entre pais e filhos.

Frente a esses dados, nota-se também a importância de novas pesquisas que enfatizem a questão do papel desempenhado pela convivência familiar no que diz respeito à propensão ou inibição do consumo de substâncias psicoativas entre os adolescentes. São necessários mais estudos visando compreender o papel da família enquanto ambiente que pode apresentar tanto fatores de risco quanto de proteção no que se refere ao uso de drogas. Assim, é necessário identificar não só quais são esses fatores, mas também como reduzir os de risco e maximizar os de proteção. Nesse sentido, outro ponto importante a ser explorado é a avaliação da percepção do funcionamento familiar tanto na visão do adolescente, considernado-se os diversos padrões de consumo de substâncias, quanto na perspectiva dos pais, pois esses dados podem trazer contribuições importantes para o planejamento de futuras intervenções de caráter preventivo.

Os planos para o futuro revelaram uma ênfase forte dada pelos adolescentes a duas questões centrais: estudar e constituir uma família. A busca pela continuidade dos estudos, representada pelo desejo de ingressar em um curso superior, demonstra a valorização atribuída à qualificação profissional como estratégia legítima para alcançar melhores condições de vida. Entretanto, seria interessante em pesquisas futuras avaliar como os adolescentes de ambos os grupos (usuários e não usuários) percebem suas reais chances de realizar suas metas no futuro, tanto em relação à escolaridade e ao trabalho, quanto no que se refere a outras conquistas, como saúde, vida afetiva, realização pessoal, casa própria, entre outros elementos comumente associados à qualidade de vida, evidenciando-se os aspectos que legitimam essa percepção.

\section{Referências}

Antón, D. M. (1998). Las drogas: Conecer y educar para prevenir. Ediciones Piramides, S.A.

Avi, M. C., \& Santos, M. A. (2000). Percepção do relacionamento familiar em mães de adolescentes usuários de drogas. Em M. A. V. Luis, \& M. A. 
Santos (Orgs.), Uso e abuso de álcool e drogas: Trabalhos apresentados no VI Encontro de Pesquisadores em Saúde Mental e V Encontro de Especialistas em Enfermagem Psiquiátrica (pp.115-125). Ribeirão Preto, SP: FIERP-EERP - USP/FAPESP.

Bardin, L. (1977). Análise de conteúdo. Lisboa: Editora Setenta.

Biasoli-Alves, Z. M. M. (2001). Crianças e adolescentes: A questão da tolerância na socialização das gerações mais novas. Em Z. M. M. Biasoli-Alves, \& R. Fischman (Orgs.), Crianças e adolescentes: Construindo uma cultura de tolerância (pp. 7993). São Paulo: Edusp.

Biasoli-Alves, Z. M. M. (2004). Pesquisando e intervindo com famílias de camadas diversificadas. Em C. R. Althoff, I. Elsen, \& R. G. Nitschke (Orgs.), Pesquisando a família: Olhares contemporâneos (pp. 91-106). Florianópolis: Papa-livro Editora.

Carranza, D. V. V., \& Pedrão, L. J. (2005). Satisfacción personal del adolescente adicto a drogas em el ambiente familiar durante la fase de tratamineto en um instituto de salud mental. Revista Latino-americana de Enfermagem, 13(especial), 836-844.

Carter, B., \& McGoldrick, M. (1995). As mudanças no ciclo de vida familiar. Porto Alegre: Artes Médicas.

Cerveny, C. M. O., \& Berthoud, C. M. E. (2001).Visitando a família ao longo do ciclo vital. São Paulo: Casa do Psicólogo.

Costa, F. T., Teixeira, M. A., \& Gomes, W. B. (2000). Responsividade e Exigência: Duas escalas para avaliar estilos parentais. Psicologia: Reflexão e Crítica, 13(3), 465-473.

Coutinho, L. G.; Insfrán, F. F. N.; Peixoto, M. V.; Gomes, R. M.; Backes, J. C.; Carvalho, H. P., \& Oliveira, F. S. (2005). Ideais e identificações em adolescentes de Bom Retiro. Psicologia \& Sociedade, 17(3), 50-56.

De Micheli, D., \& Formigoni, M. (2000). Screening of drug use in a teenage Brazilian sample using the drug use screening inventory. Addictive Behaviors, 25(5), 683-691.
Galduróz, J. C., Noto, A., \& Carlini, E. A. (1997). IV Levantamento sobre o uso de drogas entre estudantes do $1^{\circ}$ e do $2^{\circ}$ graus em 10 capitais brasileiras. São Paulo: CEBRID.

Marturano, E. M.; Elias, L. C. S., \& Campos, M. A. S. (2004). O percurso entre a meninice e a adolescência: mecanismos de vulnerabilidade e proteção. Em E. M. Marturano, M. B. M. Linhares, \& S. R. Loureiro (Orgs.), Vulnerabilidade e proteção: Indicadores na trajetória de desenvolvimento escolar (pp. 251288). São Paulo: Casa do Psicólogo; FAPESP.

Olabuenaga, J. (1996). Metodologia de la investigación cualitativa. Bilbao: Universidad de Deusto.

Oliveira, D. C., Sá, C. P., Fischer, F. M., Martins, I. S., \& Teixeira, L. R. (2001). Futuro e liberdade: $O$ trabalho e a instituição escolar nas representações sociais dos adolescentes. Estudos de Psicologia, 6 (2), 245-258.

Pedrebon, J. C. (2002). Conversando sobre sexo na família com filhos adolescentes. Em A. Wagner (Org.), Família em cena: Tramas, dramas e transformações (pp. 159-171). Petrópolis: Editora Vozes.

Penso, M., \& Sudbrack, M. (2004). Envolvimento em atos infracionais e com drogas como possibilidades para lidar com o papel de filho parental. Psicologia USP, 15(3), 29-54.

Rebolledo, E., Medina, N., \& Pillon, S. (2004). Factores de riesgo asociados al uso de drogas em estudiantes adolescentes. Revista Latino-americana de Enfermagem, 12(especial), 369-375.

Ribeiro, M. A. (1992). Relações familiares: A percepção dos filhos adolescentes. Estudos de Psicologia, 9 (1), 1-134.

Rodríguez, G. M., \& Luis, M. A. V. (2004). Estúdio descriptivo del uso de drogas em adolescentes de educación media superior de la ciudad de Monterrey, Nueva Leon, México. Revista Latino-americana de Enfermagem, 12(especial), 391-397.

Romanelli, G. (2002). Autoridade e poder na família. Em M. C. B. Carvalho (Org.), A família contemporânea em debate (pp. 73-88). São Paulo: EDUC/Cortez. 
Santos, L. M. M. (2005). O papel da família e dos pares na escolha profissional. Psicologia em Estudo, 10 (1), 57-66.

Sarti, C. A. (2004). A família como ordem simbólica. Psicologia USP, 15(3), 11-28.

Schenker, M., \& Minayo, M. C. S. (2005). Fatores de risco e de proteção para o uso de drogas na adolescência. Ciência e Saúde Coletiva, 10(3), 707-717.

Schenker, M., \& Minayo, M. C. S. (2003). A implicação da família no uso abusivo de drogas: uma revisão crítica. Ciência e Saúde Coletiva, 8(1), 299-306.

Silva, V. A., \& Mattos, H. F. (2004). Os jovens são mais vulneráveis às drogas? Em I. Pinsky, \& M. Bessa (Orgs). Adolescência e drogas (pp.3144). São Paulo: Contexto.

Simionato-Tozo, S. M. P. (2000). Ciclo de vida familiar: Um estudo transgeracional. Tese de Doutorado não-publicada, FFCLRP, Universidade de São Paulo, Ribeirão Preto.

Siminonato-Tozo, S. M., \& Biasoli-Alves, Z. M.M.(1998). O cotidiano e as relações familiares em duas gerações. Cadernos de Psicologia e Educação Paidéia, 8(14/15), 137-150.

Suárez, R. E., \& Galera, S. A. F. (2004). Discurso de los padres sobre el uso de drogas lícitas e ilícitas percibido por estudiantes universitários. Revista Latino-americana de Enfermagem, 12(especial), 406-411.

Sudbrack, M. F. O. (2001). Terapia familiar sistêmica. Em S. D. Seibel, \& A. Toscano Jr (Org.), Dependência de drogas (pp. 403-415). São Paulo: Ed. Atheneu.

Toscano Jr., A. (2001). Adolescência e drogas. Em S. D. Seibel, \& A.Toscano Jr (Ed.), Dependência de drogas (pp. 283-302). São Paulo: Ed. Atheneu.

Wagner, A., Carpenedo, C., Melo, L. P., \& Silveira, P. G. (2005). Estratégias de comunicação familiar: A perspectiva dos filhos adolescentes. Psicologia: Reflexão e Crítica, 18(2), 277-282.
Wagner, A., Falcke, D., \& Meza, E. (1997). Crenças e valores dos adolescentes acerca da família, separação e projetos de vida. Psicologia: Reflexão e Crítica, 10(1), 155-167.

Wagner, A., Falcke, D., Silveira, L. M. B. O., \& Mosmann, C. P. (2002). A comunicação em famílias com filhos adolescentes. Psicologia em Estudo, 7(1), 75-80.

Endereço para Correspondência:

Elisângela Maria Machado Pratta. Rua Episcopal, 2474, ap. 154 A, Vila Lutfalla II, 13560580, São Carlos-SP, Brasil. E-mail: emmppsic@scl.terra.com.br

Artigo recebido em 31/07/2006.

Aceito para publicação em 16/04/2007.

Agência de fomento: CAPES

Trabalho baseado na Dissertação de Mestrado intitulada: "Adolescência, drogadição e família: Caracterização do padrão de consumo de substâncias psicoativas e avaliação da percepção dos pais em adolescentes do ensino médio", defendida em 2003 junto ao Programa de Pós-graduação em Psicologia da Faculdade de Filosofia, Ciências e Letras de Ribeirão Preto-SP, USP.

Elisângela Maria Machado Pratta é Mestre em Ciências, Área de Concentração: Psicologia e Doutoranda pelo Programa de Pós-graduação em Psicologia da Faculdade de Filosofia, Ciências e Letras de Ribeirão Preto-SP, USP.

Manoel Antônio dos Santos é Doutor em Psicologia Clínica e Professor Doutor do Departamento de Psicologia e Educação da Faculdade de Filosofia, Ciências e Letras de Ribeirão Preto-SP, USP. 